\title{
Jia, Lianxiang 賈連翔, Collected Annotations of the Unearthed Numerical Hexagrams' Texts 出土數字卦文
} 獻輯釋

\author{
Shanghai 上海: Zhongxi Shuju 中西書局, 2020, 305 pages
}

\section{Sutong $\mathrm{HAO}^{1}$}

Accepted: 31 August 2021 / Published online: 13 November 2021

(C) The Author(s) 2021

The so-called "numerical hexagrams" (shùzì guà 數字卦) discovered in unearthed texts on Shang-Zhou 商周 oracle bones, bronzes, and potteries, as well as on Warring States period's bamboo slips, are extant relics of divination events of high Chinese antiquity. These hexagrams are recorded with graphs of numbers as vertical number sets (2), numbers thus representing what are in later traditionally transmitted hexagrams broken and solid lines (yīnyáng yáo 陰陽爻). Research on this subject formally started in the late 1980s, promoting the Zhouyi 周易 (Book of Changes) studies in contemporary China. The concept and the relevant issues put forward between 1985 and 1988 have long been attributed to Zhang Zhenglang 張政烺 (ZhANg Zhenglang, and Li Ling 李零, eds. 2012. Collected Papers on the Yi's Discussions 論易叢 稿 [Beijing 北京: Zhonghua Shuju 中華書局], 1-72). Based on various speculations about the origin of the broken and solid lines in the Zhouyi during the first half of the twentieth century, reflections on this thought-provoking theme accelerated from 1999 onwards because of Li Xueqin's 李學勤 pioneering disapproval of Zhang's studies (Ding Sixin 丁四新. 2018. "On the Stages, Contributions, and Finality of the Study of Numerical Hexagrams 數字卦研究的階段、貢獻及其終結.” Studies of Zhouyi 周易研究 5: 45). Thus, the concept of “numerical hexagrams" became a conventional name widely accepted by Chinese scholars. According to DiNg Sixin, during the last four decades research on this subject has solved three major problems. This has been truly path-breaking progress and represents a landmark achievement in the history of modern Chinese humanities (DING Sixin. 2019. "Analyses of the Numerical Hexagrams and Related Conceptions 數字卦及其相關概念辨析." History of Chinese Philosophy 中國哲學史 3: 30). The book under review, a revised version of Jia's Ph.D. thesis, is his first work on Chinese history $(303,305)$. As Edward L. Shaughnessy

Sutong HAO

sutong.hao@campus.lmu.de

1 Institute of Sinology, Department of Asian Studies, University of Munich, Kaulbachstr. 51 a, 80539 Munich, Germany 
writes, Jia has faithfully followed and practiced the teachings of his supervisor, the well-known Chinese scholar Li Xueqin, whose academic influence can be recognized on every page of this book. Although Jia considers this book a preliminary study, it indeed greatly contributes to the understanding of unearthed hexagrams (Pref. 1, 4).

Jia's book is divided into seven parts. In the Introduction, Jia declares that this book has taken full advantage of the unique connection between the unearthed hexagrams and the Tsinghua 清華 bamboo slips' Shifa 筮法 (Divinatory Method) text. Then Jia introduces technical terms and research methodologies applied throughout the book. Although the concept of "numerical hexagram" has been criticized, Jia decided to continue to use it due to its common usage by previous scholars (2). Criticism has arisen because the ancients never used this term in early China; even ZHANG Zhenglang simply named the unearthed hexagrams either "Yi hexagram" (yìguà 易卦), “divinatory number” (shìshù 筮數), or “divinatory hexagram” (shìguà 筮卦) (Zhang and Li 2012: 1-72). Long-lasting confusion about how these constellations of lines should be properly termed has had a limiting influence on research. The situation was once described as follows: "As materials became richer and richer, the articles became more and more complicated, and the issues more and more confusing" (XING Wen 邢文. 2007. "Problems in Numerical Allograms and the Composition of the Zhouyi 數字卦與《周易》形成的若干問題." Bulletin of the Department of Chinese Literature N.T.U. 臺大中文學報 27: 10). For instance, Jia is reluctant to call the hexagrams in early manuscript Zhouyi texts, such as the Tsinghua bamboo slips' Biegua 別卦 (The Sixty-four Hexagrams), “numerical hexagrams" because their divinatory numbers representing the "hexagram graph" (guàhuà 卦畫) are model hexagrams rather than records of historical divination events (2). He once provided a negative answer to this question while considering these materials not as the subject of the present book (JIA Lianxiang. 2014. "Overview of Research on the Unearthed Numerical Hexagrams’ Texts 出土數字卦材料研究綜述.” Trends of Recent Researches on the History of China 中國史研究動態 4: 40) (2).

Following XIAO Hanming 蕭漢明 and XU Xitai 徐錫臺, Ding argues for changing the term "numerical hexagram" to "numerical-graph-lines hexagram" (shùzì yáohuà guà 數字爻畫卦) or “numerical-lines hexagram” (shùzì yáoguà 數字爻卦) (Ding 2018: 43, 46; Ding 2019: 34). Two main reasons lend support to Ding's argument. First, this conventional concept has only been in use in contemporary Chinese academic history but does not belong to traditional Zhouyi terminology. On the one hand, all kinds of $Y i$ hexagrams were derived from divinatory numbers, so by the notion of "numerical hexagram" one cannot distinguish any kind of hexagrams from another type. On the other hand, the traditional concepts are sufficient for contemporary academic discussions (Ding 2019: 59). Second, even though the lines of the unearthed hexagrams are numbers, the plausible name "numerical hexagram" does not qualify as a technical term. Every hexagram of the Zhouyi is formed by six lines, so the term "hexagram graph" relies on the "line graphs" (yáohuà 爻畫). For a hexagram graph recorded as a number set, each number in the line position (yáowèi 爻位) can represent a line graph in its own right. All the six (or three) line graphs of a hexagram (or trigram) graph correspond to numbers, and the whole of the hexagram (or trigram) graph indeed represents its "hexagram image" (guàxiàng 卦象) rather than a six-digit 
(or three-digit) number, no matter in which way the lines are written. In short, according to Ding the name "numerical hexagram" is inaccurate since the hexagram image represents the unit for any hexagram in the Zhouyi system (Ding 2018: 50-51).

Chapter 1 of Jia's book consists of seven sections. As there is no corresponding record of the numerical-lines hexagrams in any ancient book, Jia first provides a detailed overview of divination-related materials in transmitted documents from the pre-Qin 秦 period to the early Han 漢 era. Based on previous studies, he singles out individual problems of traditional Zhouyi studies and advances the knowledge regarding each of them. Jia proposes to ascribe the intellectual content contained in the Yijing's 易經 hexagram names (guàmíng 卦名) and hexagram sequences (guàxù 卦序) to ancient writers and compilers writing in the transition period during which the Zhouyi developed into a philosophical text. Since it was the essential symbol within the much earlier divination processes, the hexagram graph serves as a bridge between the ancient divinatory method (shifă 筮法) and later philosophical ideas (14). As far as the Yizhuan 易傳 is concerned, Jia suggests that the received Shuogua 說卦 (Explanation of the Hexagrams) text might have combined multiple extracts from various preceding homogeneous documents, and therefore many of its ideas are consistent with pre-Qin thinking. Given the nature of its origin, the Shuogua is not a text with extremely consistent ideas (21). Drawing information from the Hongfan 洪範 (The Great Plan) and the Zhouli 周禮 (Rites of Zhou), Jia argues that from the Western Zhou 周 to the Spring and Autumn period, more and more officials in the central government and the vassal states were gradually allowed to specialize in divination (30). Moreover, Jia touches on issues about the three $Y i$ recorded in the Zhouli. He proposes that two different ancient texts may have borne the same title Guicang 歸藏 (Return to the Hidden). The one recorded in the Zhouli might be in concord with what Confucius called the Kunqian 坤乾 (The Hexagrams Kun and Qian). The other Guicang, namely the manuscript recovered among the Wangjiatai 王家台 bamboo strips and the corresponding version of traditionally transmitted fragments collected by MA Guohan 馬國翰, might be a divinatory book circulated in the Warring States period (34). As for the divination records in the Zuozhuan 左 傳 (The Zuo Traditions) and the Guoyu 國語 (Discourses of the States), Jia has found 22 pieces of records from seven states. A striking exception is the state of Chu 楚, which stands in stark contrast to the many divination texts unearthed from the Chu in modern times. Jia argues that the Zhouyi system must have been the dominating divinatory system by that time (45). The last two sections concern the connection between the Zhouyi and the pre-Qin masters and the generation of early Han thinkers (45-57).

The content described above comprehensively examines the development of $Y i$ studies in their primary stage. With them, Jia provides detailed background knowledge about the broad spectrum of divination-related materials. Thus, Chapter 1 forms a well-documented basis for further research on the numerical-lines hexagrams. The chapters that follow, however, fall short of exploring these subjects more extensively. For example, only the 3rd section of Chapter 3 touches on issues about the three $Y i$ recorded in the Zhouli, the 4th section of Chapter 5 mentions a divinatory case in the Zuozhuan and the $Y i$ studies from the Chu, and the 5th section of Chapter 5 discusses the Shuogua and the three Yi (201-202, 
277-280, 281-284). None of the other subjects are further discussed in other parts of this book. Furthermore, Jia overlooks the possible linkages among themes covered in different chapters. For instance, the 1st section of Chapter 1 illustrates concepts of time in the Yijing (9-11), while the 1st section of Chapter 5 discusses concepts of time in the Shifa (255-257). It leaves it to readers to make these connections and to develop new ideas for further research. Finally, it should be pointed out that in the 1st section of Chapter 1, Jia makes the same mistake twice: he transcribes the graphs of the broken lines in the Shuanggudui 雙古堆 bamboo strips' Zhouyi into the divinatory number $6(12,14)$, but they should be number 8 as is evident from previous research, since they are identical with those on the Mawangdui 馬王堆 silk manuscripts' and the Shanghai Museum bamboo slips' Zhouyi.

Chapter 2, which deals with 88 pieces (or groups) of unearthed oracle bones, bronzes, potteries, and bamboo slips, provides a list of 138 numerical-lines hexagrams in the order of their dates, categories, and regions (285). Chapter 3 presents an overview of the research on these excavated materials. Jia proposes to classify them according to two aspects. As far as date and region are concerned, the Warring States period's Chu numerical-lines hexagrams, which appear as two six-line hexagrams or four three-line trigrams, are different from those of the Shang 商 dynasty and Western Zhou era (197). As far as the system of the divinatory numbers is concerned, Jia has developed Li's hypothesis, namely distinguishing two systems that separately used the divinatory number 1 or 7 (200-201). He argues that the Chu numerical-lines hexagrams represented by the Shifa should belong to the system using the divinatory number 1 (286). Next, Jia proposes that the numerical-lines hexagrams are closely associated with the philosophical thinking of the Zhouyi. The earlier the time, the unclearer the boundary between unearthed hexagrams and $Y i$ studies. Thus, from the Western Zhou era to the Warring States period, an outline of the development of the Zhouyi system can approximately be reconstructed (203-204).

Chapter 4 uses the published Tsinghua bamboo slips' transcriptions as its base text to emend the Shifa. Each of the 30 sections includes traced copies, transcriptions, original comments, and interpretations (205). Shaughnessy recommends Jia's layout to be the standard method of the bamboo and silk manuscript studies (Pref. 1-2). Chapter 5 concerns the numerical-lines hexagrams from the Chu and the Shifa. First, Jia examines the divination cases from the Chu according to the divinatory methods of the Shifa. Based on their consistency he argues that the excavated Chu hexagrams and the Shifa belong to the same divinatory system (270). Jia then deduces the divinatory method of Chu numerical-lines hexagrams. By adapting the traditional divinatory method of the received Xici 熬辭 (Appended Statements), namely changing taking out a piece of yarrow straw to a bundle of yarrow straws, he concludes that they use the same divinatory numbers as the Shifa. According to Jia, the divinatory method of the Xici might thus have developed from the Chu divinatory system (270-277). Furthermore, Jia ranks the four divinatory numbers, namely $8,5,9$, and 4 in the order of their ratios of occurrence in his calculation. This sequence accords with the Chu numerical-lines hexagrams and the Shifa's 2nd and 29th Sects. (271-272). Jia also argues that one special divination case from the state of Lu 魯 in the Zuozhuan corresponds to the Shifa (280). As mentioned above, 
he refers to the Shuogua again to further examine its relationship with the Shifa, and he thinks that it might be in some way related to the Lianshan 連山 (Joint Mountains) and Guicang (280-284).

The last part of this book summarizes the main arguments. Jia cautiously reminds his readers that his deductions are based on only provisional statistics provided by the unearthed hexagrams that one can dispose of today (286). This warning implies that a reassessment of the core arguments of the 2nd section of Chapter 3 and the 3rd section of Chapter 5 is necessary. Should more numerical-lines hexagrams be discovered, new statistics could change Jia's conclusions about the divinatory numbers' systems, and his inferences from the system using the divinatory number 1 in the Chu could become invalid. Moreover, it should be pointed out that neither Jia's modification of the received Xici nor the adaptation put forward by CHENG Hao 程 浩 can be considered fully convincing (273). Readers should be aware that there are endless possibilities for how the algorithm of Zhouyi divination can vary.

This book undoubtedly lays a new foundation for research on pre-Qin Yi studies and unearthed Zhouyi manuscript studies. Anyone interested in these themes should not miss this book. Yet, as more materials have been discovered recently (305), problems of the excavated $Y i$ hexagrams, $Y i$ divination, and other subjects will remain hotly debated topics.

Funding Open Access funding enabled and organized by Projekt DEAL.

Open Access This article is licensed under a Creative Commons Attribution 4.0 International License, which permits use, sharing, adaptation, distribution and reproduction in any medium or format, as long as you give appropriate credit to the original author(s) and the source, provide a link to the Creative Commons licence, and indicate if changes were made. The images or other third party material in this article are included in the article's Creative Commons licence, unless indicated otherwise in a credit line to the material. If material is not included in the article's Creative Commons licence and your intended use is not permitted by statutory regulation or exceeds the permitted use, you will need to obtain permission directly from the copyright holder. To view a copy of this licence, visit http://creativecommons.org/licen ses/by/4.0/.

Publisher's Note Springer Nature remains neutral with regard to jurisdictional claims in published maps and institutional affiliations. 